\section{La vivienda en La Habana Vieja. Desarrollo histórico, problemática actual y programas en curso}

\author{
Madeline MenÉndez García \\ Plan Maestro, Oficina del Historiador de la Ciudad \\ Dirección elect.: madeline@planmaestro.ohch.cu \\ Tfno: 8604311
}

\begin{abstract}
Resumen
La arquitectura doméstica de la Habana Vieja, protagonista principal de su imagen urbana, presenta un variado repertorio asociado, de manera fundamental, a las características tipológicas de la tradicional casa patio, en su tránsito por más de cuatro siglos de historia. A pesar de los problemas habitacionales que acumula la Ciudad en su conjunto y que en las más antiguas áreas centrales se traducen en sobreocupación y deterioro, La Habana Vieja conserva los altos valores patrimoniales que le han sido reconocidos, proporcionados principalmente por su arquitectura, sus ambientes urbanos y su vitalidad. El carácter integral que persigue el programa de rehabilitación del Centro Histórico y que logra materializarse gracias a su novedoso modelo de gestión, ha posibilitado la incorporación de diversos programas de atención a la vivienda. Con ellos se intenta enfrentar el reto que implica conservar el carácter residencial del conjunto recuperando, al mismo tiempo, la vivienda digna y confortable aspirada.
\end{abstract}

Palabras clave: Centro histórico, patrimonio, tipología doméstica, rehabilitación integral, modelo de gestión.

\footnotetext{
Abstract

The domestic architecture of Old Havana, a key aspect of its urban image, presents a variety of problems fundamentally associated with typological characteristics of the traditional house with courtyard and its development over more than four centuries of history. In spite of housing problems in the city as a whole and the fact that the oldest central areas are overcrowded and in a state of deterioration, Old Havana retains high heritage values, provided principally by its architecture, its urban ambience and its vitality. The comprehensiveness of the restoration program in the Historic Center which has been made possible by a new administration model, has led to the incorporation of diverse programs focusing on housing. These form part of an attempt to meet the challenge of preserving the residential nature of the area while at the same time providing decent and comfortable housing.
}

Key words: Historic center, heritage, domestic typology, comprehensive restoration, administration model.
El Centro Histórico La Habana Vieja, con una extensión de $2.14 \mathrm{Km}^{2}$, ocupa prácticamente el $50 \%$ del territorio municipal del mismo nombre y la mayor parte de los sectores residenciales de este último. $\mathrm{Al}$ interior del Centro Histórico se conservan unas 3400 edificaciones representativas de cinco siglos de actividad constructiva.

Aún cuando de su condición de centralidad se deriva la fuerte presencia de notables exponentes de la arquitectura civil pública, es precisamente la arquitectura doméstica la que, con su peso dominante, — correspondiente al 81,5\% de las edificaciones - proporciona la unidad y la coherencia al conjunto urbano. La arquitectura religiosa, con mucho menos peso, la acompaña, como acentos contrastantes que incorporan variedad e interés al tejido urbano. Por último, se conservan, en su condición de más antiguos testigos, los valiosos exponentes del sistema defensivo de la Ciudad.

El alto valor patrimonial del conjunto edificado lo demuestra la conservación de un $88 \%$ de inmuebles clasificados con los Grados de Protección del I al III, entre los cuales, 516 ostentan los más altos valores otorgados, es decir los Grados de Protección I y II, en correspondencia con su categoría cultural.

De estas edificaciones, el mayor volumen corresponde a la primera mitad del siglo $\mathrm{XX}$, representando estas el $56,4 \%$. Ello coincide con la fuerte actividad constructiva que acompañó a la naciente república, fundamentalmente en las primeras décadas de dicho siglo. Actualmente las edificaciones vinculadas a la totalidad del siglo XX representan el $66,5 \%$ del fondo inmobiliario.

Dentro de los límites del Centro Histórico residen 66,742 habitantes — según Censo de mayo del 2001- en las 22,623 viviendas incluidas. De dicho total de viviendas 10,251 , o sea, el 45,3\%, no reúne las condiciones de habitabilidad adecuadas integrando a una parte de los inmuebles devenidos en "ciudadelas» ${ }^{1}$ o que surgieron como cuarterías $^{2}$. En estas se aloja el $41,5 \%$ de la población residente.

Son precisamente estas edificaciones las que concentran los peores estados constructivos en consecuencia con dicha modalidad de uso. En general las viviendas presentan un alto deterioro - asociado a fallas estructurales en cubiertas y filtraciones - en un $47 \%$ de los casos; un deterioro medio - con grietas menores en muros y problemas sanitarios - en un 39\%; mientras que las viviendas restantes se consideran en aceptable estado aunque muchas de ellas requeridas de acciones preventivas de mantenimiento.

\footnotetext{
${ }^{1}$ Denominación dada a las grandes casas coloniales que fueron convertidas en casas de inquilinato con un uso intensivo y especulativo.

${ }^{2}$ Edificaciones que fueron concebidas para un conjunto de vivienda mínima y especulativa, simples habitaciones con servicios de carácter colectivo.
} 


\section{EVOLUCIÓN HISTÓRICA DE LA ARQUITECTURA DOMÉSTICA}

\section{La etapa colonial}

Una vez superadas las etapas iniciales caracterizadas por el empleo de materiales rústicos no perdurables y por la dispersión de las viviendas, comienza un desarrollo constructivo que introduce materiales de una mayor solidez y que queda entonces condicionado por el régimen de medianería.
La vivienda incorpora entonces el patio, como solución ecológica, alrededor del cual se dispondrían entonces las diferentes funciones domésticas. De este modo comienzan a definirse organizaciones distributivas que, en su reiteración y su evolución histórica, irán estableciendo la estructura tipológica de la arquitectura doméstica.

Durante un largo período — hasta finales del siglo XVIIpredominó la edificación baja, resuelta con cubiertas inclinadas y de sencillas expresiones de influencia hispano-mu-
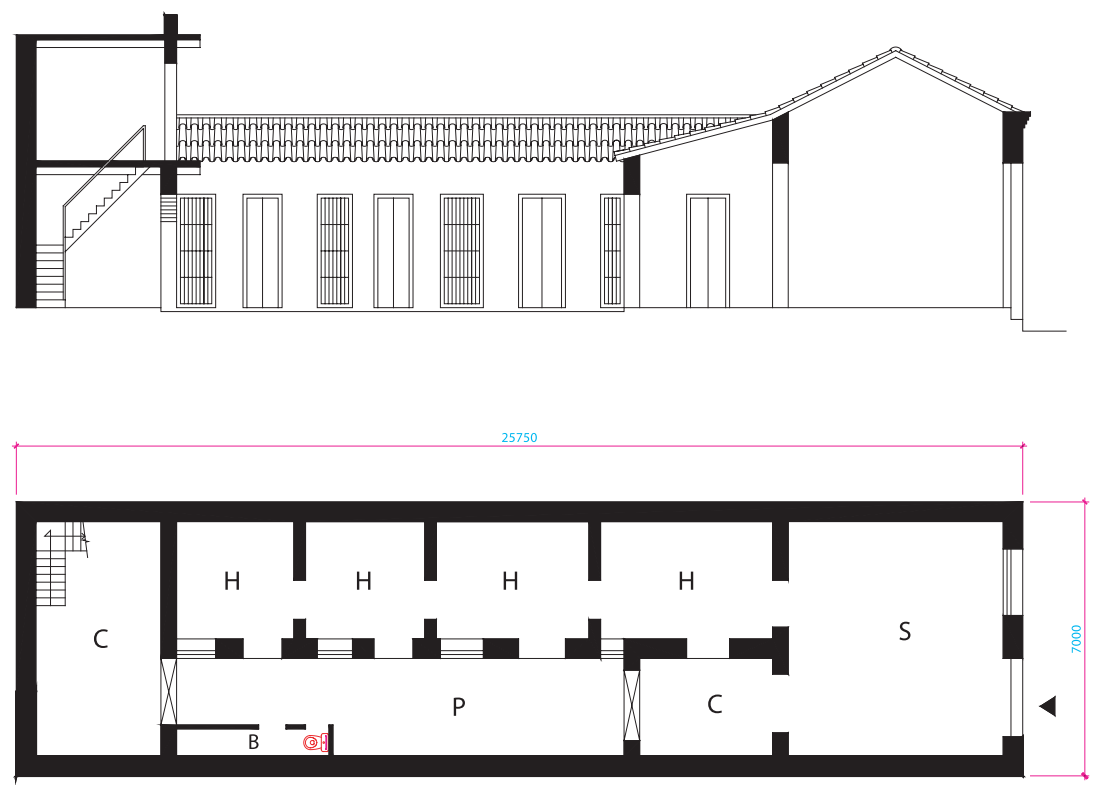

Empedrado 359, casa del siglo XVIII

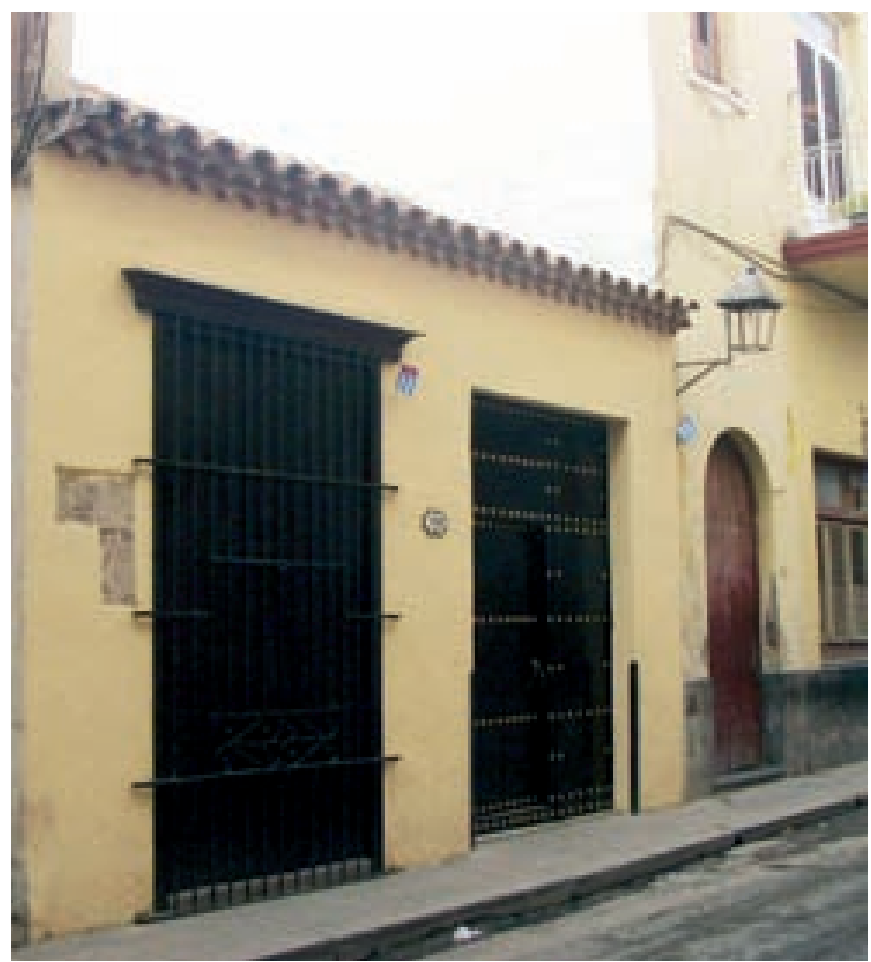

Fachada de Amargura 255, siglo xVIII

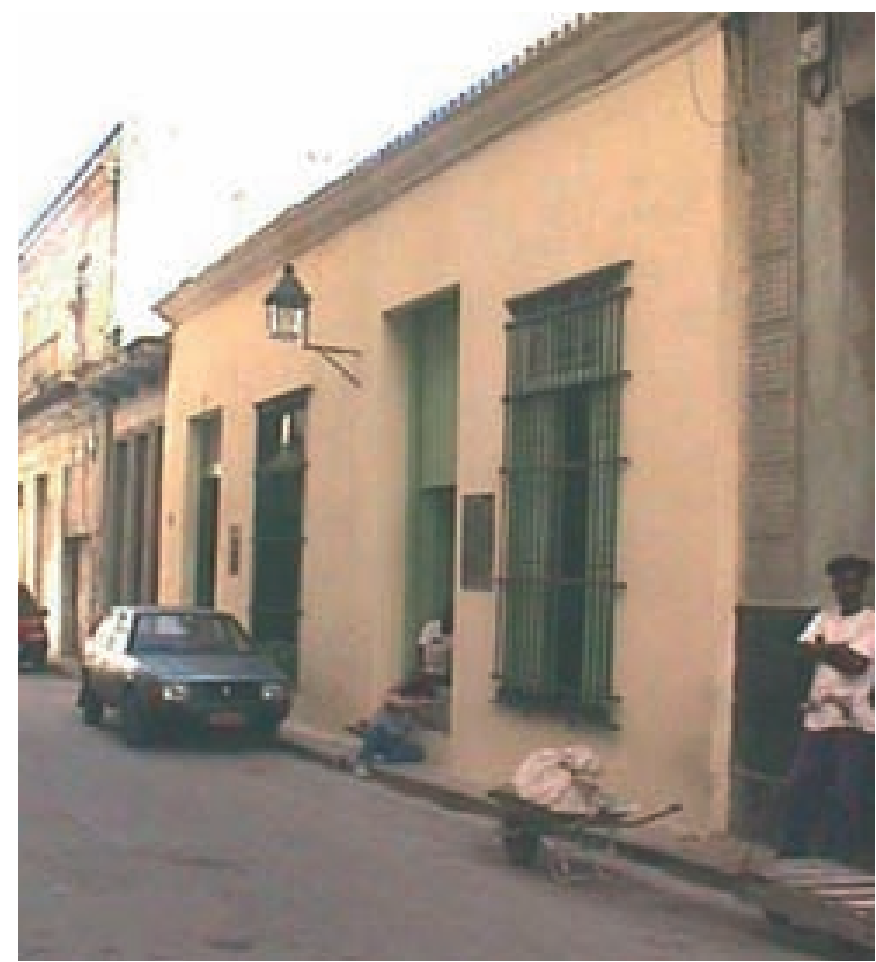

Fachada de Empedrado 357-359, casas gemelas del siglo XVIII 


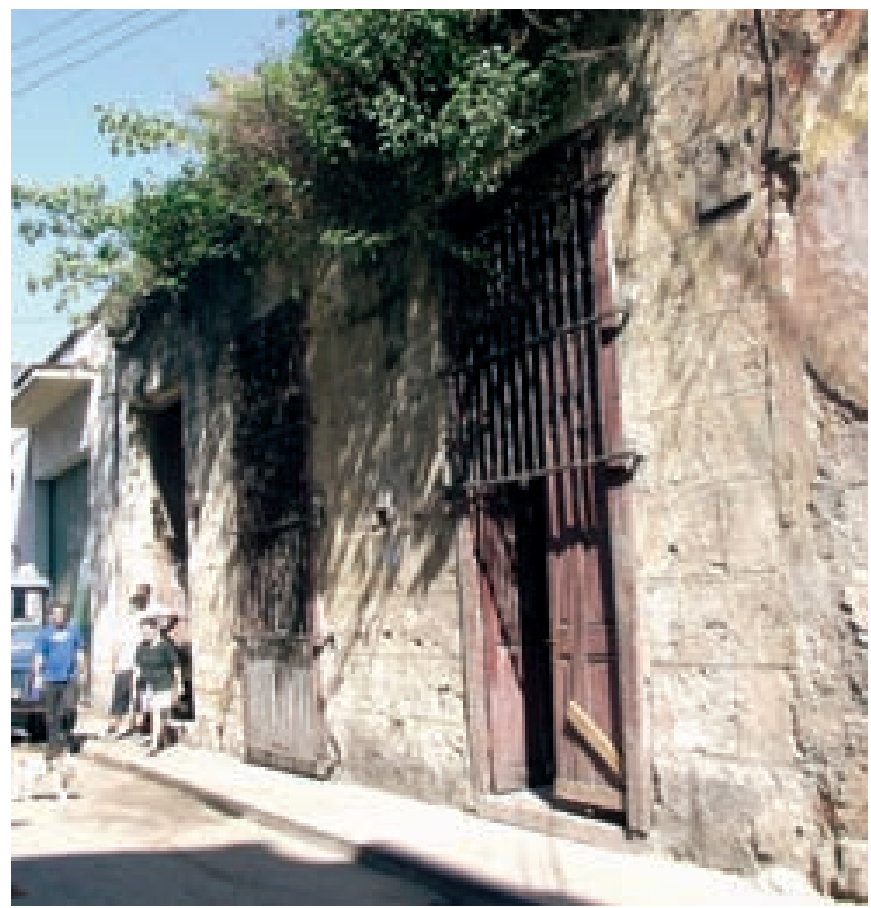

San Ignacio 603 , solución con zaguán; fachada y planta de la misma

déjar. Las soluciones espacio-funcionales más simples corresponden a la casa que presenta un local único ocupando la primera crujía, la sala, así como proporciones alargadas que incluye el patio lateral. Este tipo se extendería, con mínimas variaciones, a lo largo del tiempo, aún hasta las primeras décadas del siglo XX.

Se incorpora algo después a la vivienda el zaguán — dentro del propio siglo XVII-, solución de acceso derivada de la aparición de las primeras modalidades de transporte. Ello demanda la ocupación de un lote más ancho con el cual se

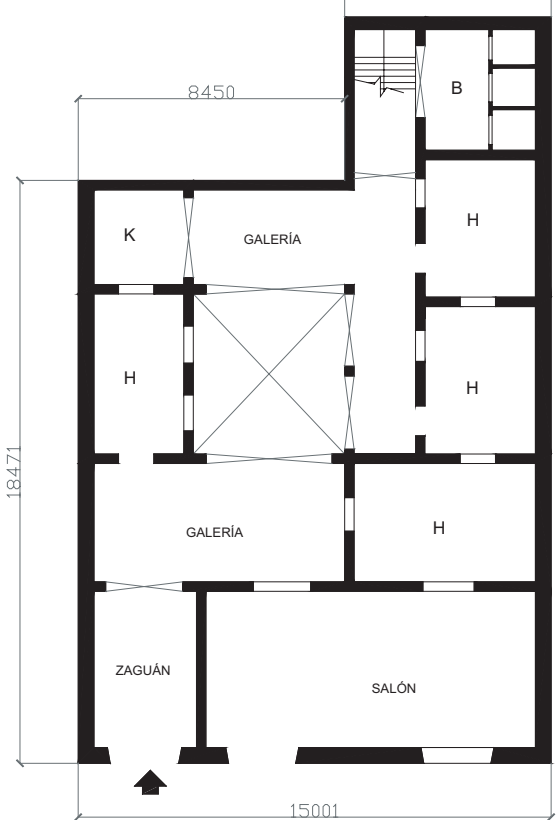

SAN IGNACIO 603

posibilita la aparición de galerías perimetrales al patio, y este, en ocasiones, logra desarrollar un carácter central respecto a los restantes locales de la vivienda.

Este nuevo tipo doméstico, vinculado a los grupos sociales económicamente más fuertes, evoluciona más tarde en las llamadas «casas altas» resueltas en dos niveles, aunque no es hasta el siglo XVIII que dicho crecimiento en altura adquiere un peso mayor derivado de la saturación del espacio intramural y apoyado entonces en el dominio de las técnicas constructivas.

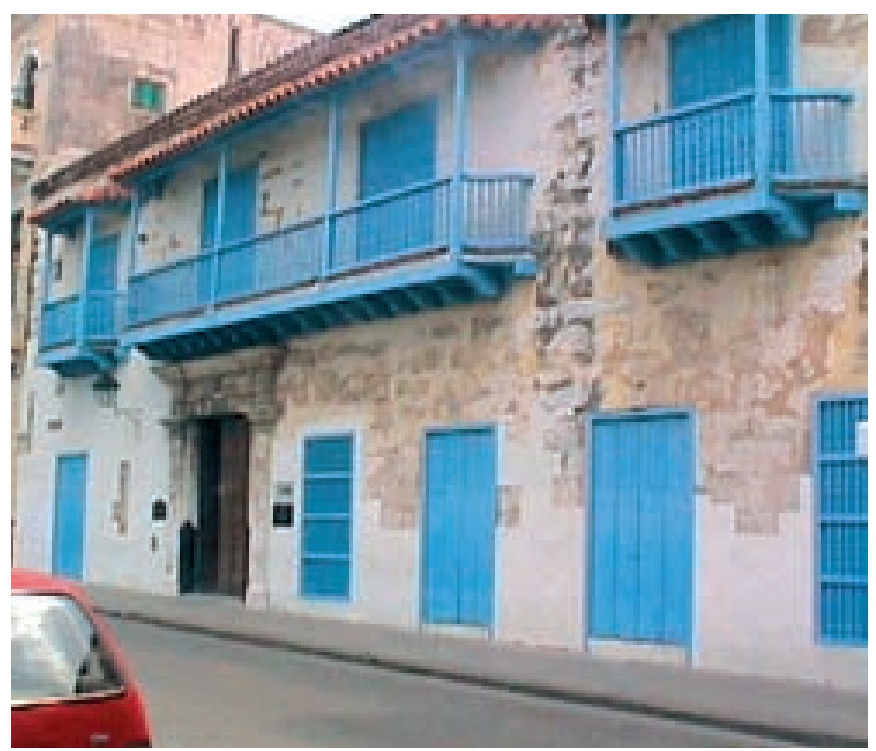

Fachada y planta baja de Tacón 12, casa del siglo VIII

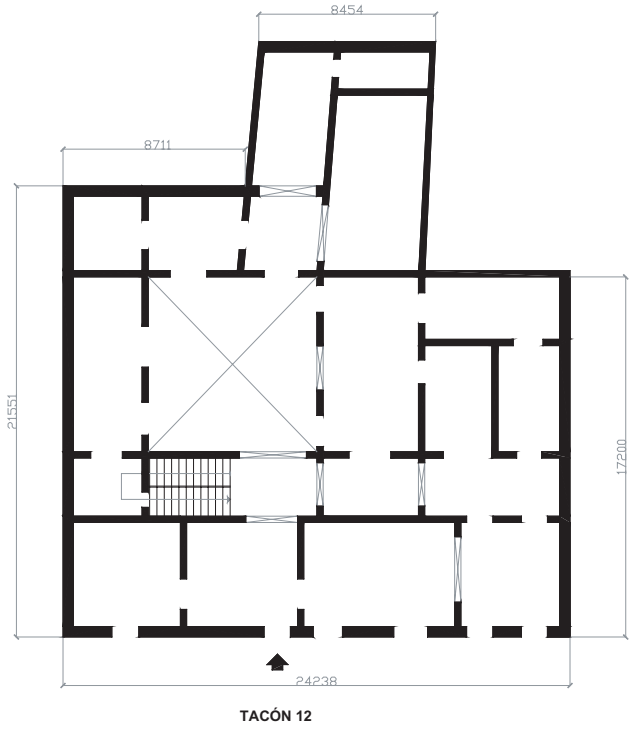



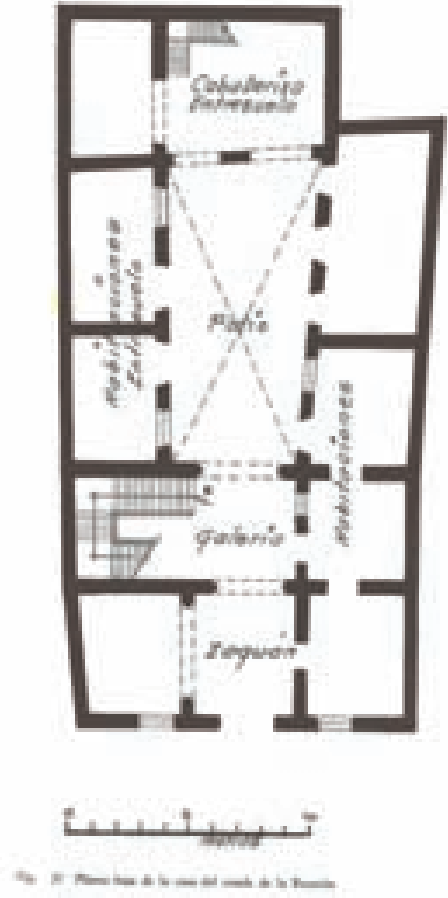

Empedrado 213: Casa de la Condesa de la Reunión. Plantas y vista interior. Inicios del siglo XIX

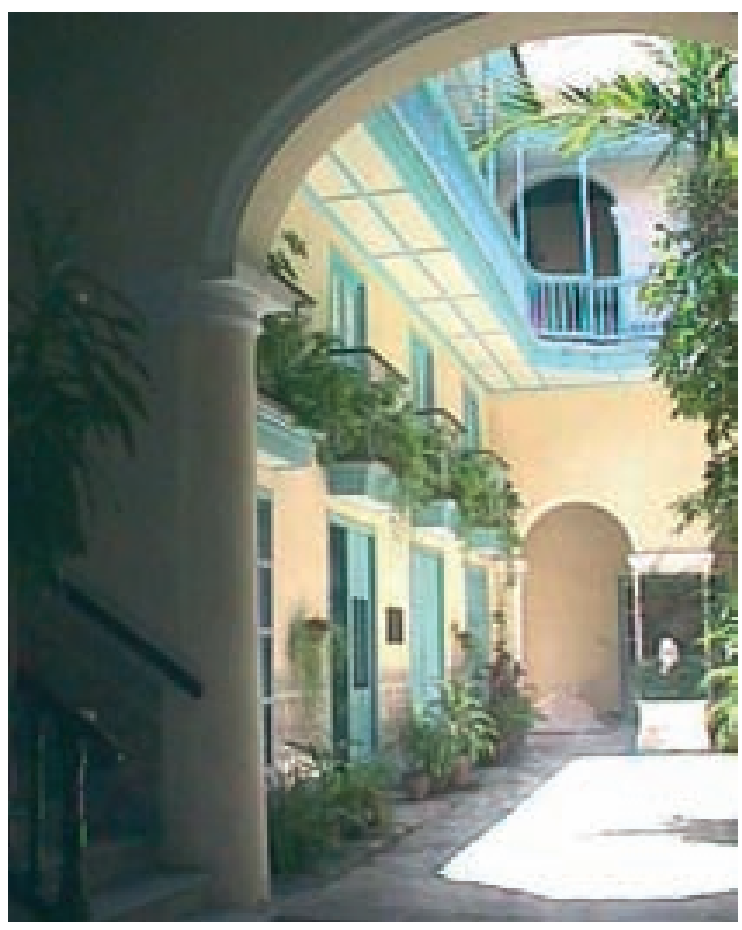

El auge de la producción azucarera en este siglo propicia el enriquecimiento de muchas familias habaneras que expresan su poder en la construcción de amplias casonas palaciegas que ocupan entonces los sitios más privilegiados del conjunto urbano. De este modo se incorpora la solución con entresuelo y con él se perfecciona una clara y precisa segregación de funciones a escala del inmueble. Las áreas de almacenaje, los sitios para los coches y las caballerizas se apropian de la planta baja, directamente vinculada a la vida urbana. El entresuelo dispondrá de las habitaciones para la servidumbre así como las oficinas y el despacho del propietario. Finalmente, la verdadera vida familiar se desarrolla en el piso alto, sitio privilegiado desde el punto de vista climático y en cuanto a sus condiciones de privacidad.

Estas soluciones domésticas se extenderán luego al siglo XIX sin importantes modificaciones tipológicas. Los cambios quedarán limitados al empleo de nuevos materiales y técnicas constructivas así como al paso de las cubiertas inclinadas a las cubiertas planas. Por su parte las expresiones formales adoptarán los códigos del neoclasicismo. Es en este siglo cuando la casa colonial adquiere el esplendor y el refinamiento exigido por el buen gusto de sus aristocráticos dueños al mismo tiempo que logra su mejor acondicionamiento a nuestras exigencias climáticas.

Mientras tanto, la vivienda vinculada a la población de menos recursos se mantendrá dentro de las soluciones uniplantas más simples, ocupando los lotes más estrechos y las localizaciones menos jerarquizadas respecto al conjunto urbano.

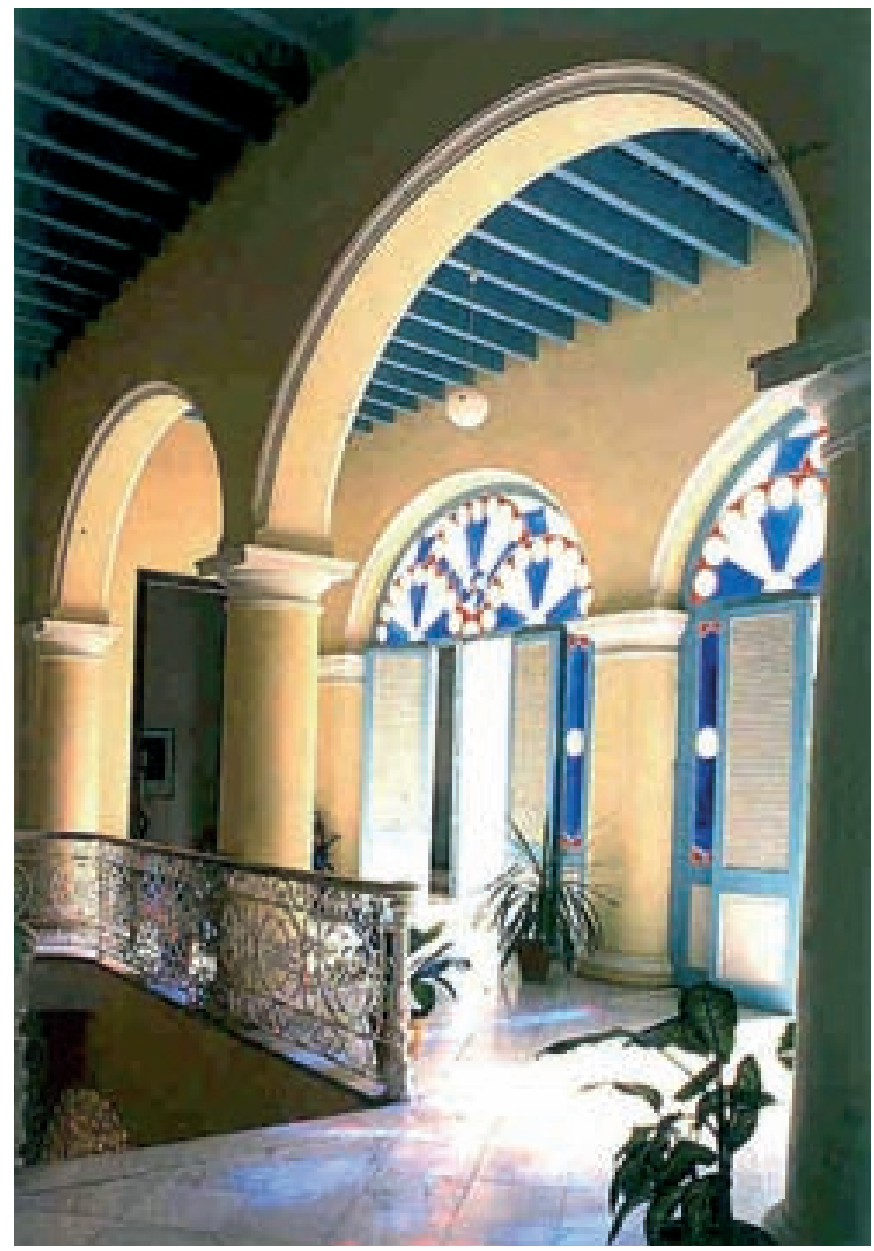

Vista interior de Mercaderes 160, casa del siglo XIX 
A mediados del siglo XIX, con el traslado hacia otras áreas urbanas de la ciudad en expansión de las familias económicamente más fuertes, comienza a producirse un cambio notable en cuanto al comportamiento de la estructura residencial de La Habana Vieja. El mismo se traduce, por una parte, en el incremento de las sustituciones edilicias, y por otro, en las adecuaciones al nuevo régimen del inquilinato de gran parte de las amplias casonas coloniales que resultaban vendidas por sus antiguos propietarios.

La opulenta casa derivaría entonces en el modesto hábitat de numerosas familias humildes, —la llamada «ciudadela» — dentro de una nueva intensidad de uso, más intensa y especulativa. Entre las transformaciones más comunes que se operaron en dicho fondo residencial pueden señalarse:

- La creación de una batería de servicios sanitarios comunes desarrollada generalmente sobre una parte de las galerías posteriores, o al interior de una de las habitaciones más retiradas hacia el fondo de la edificación. Otra alternativa de ubicación sería dentro del propio patio junto al muro medianero.

- La adaptación de un local destinado a cocina que incluyó el fogón de carbón con su campana y chimenea, así como algunas mesetas, éste, generalmente ubicado en la última crujía de la casa.

—La división de algunos locales principales para desarrollar habitaciones más pequeñas.

- La independización, sobre todo en casas que ocupaban lotes de esquinas, de locales de las plantas bajas que asimilarían funciones comerciales y alterarían la expresión de las fachadas.

- La independización de toda una planta baja que sería adaptada al uso comercial o productivo. Las transforma-

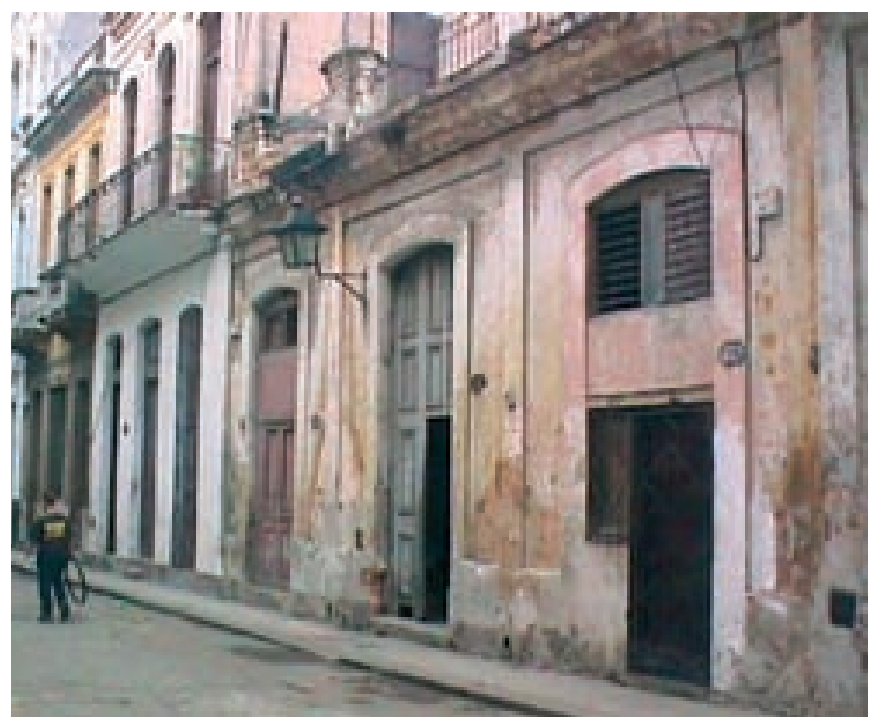

Cuartería en Porvenir 11, fachada y planta, siglo XIX

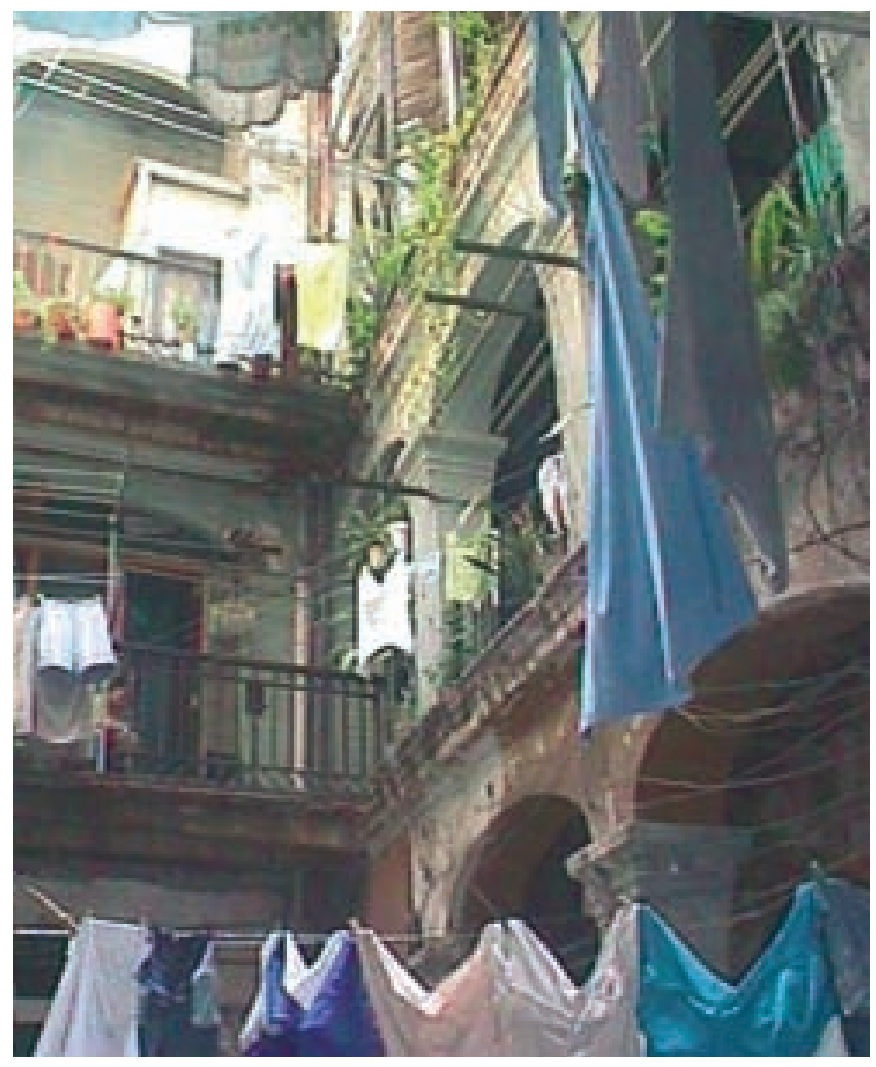

Interior de ciudadela en Teniente Rey 113

ciones para ello necesarias consistieron en la incorporación de una estructura columnar arquitrabada que asimilaría las cargas murarias de los pisos altos; la modificación de las soluciones de acceso; el sellaje de los patios interiores y la ampliación de los vanos de las fachadas.

Una alternativa aún más especulativa se incorporaría con la solución conocida como «cuartería». Se caracteriza 

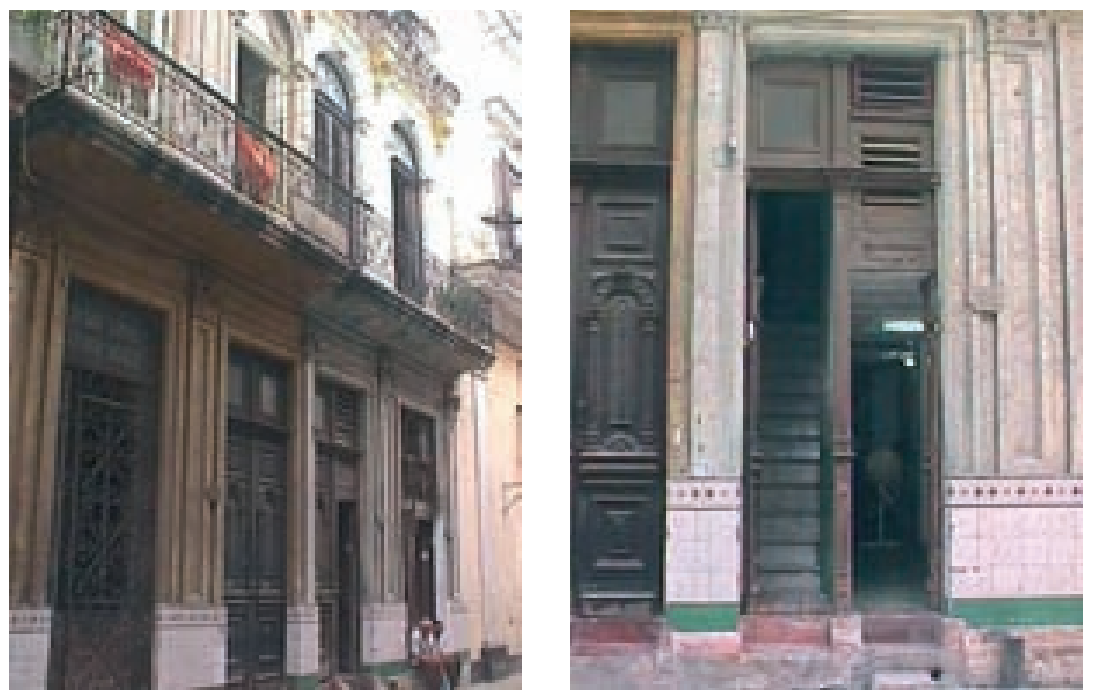

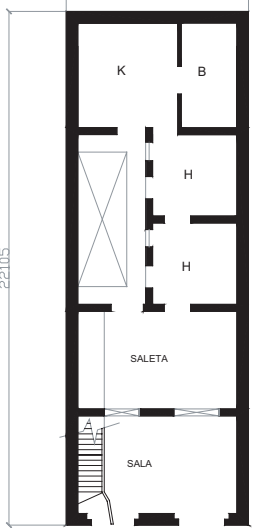

PLANTA BAJA.
HABANA 162

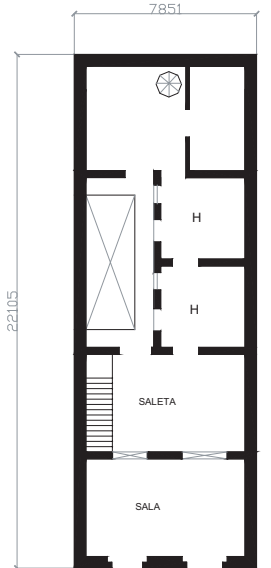
PLANTA ALTA.
HABANA 162

Casas gemelas, de sala y saleta, en Habana 162. Inicios del siglo xx. Fachada, detalle de accesos y plantas

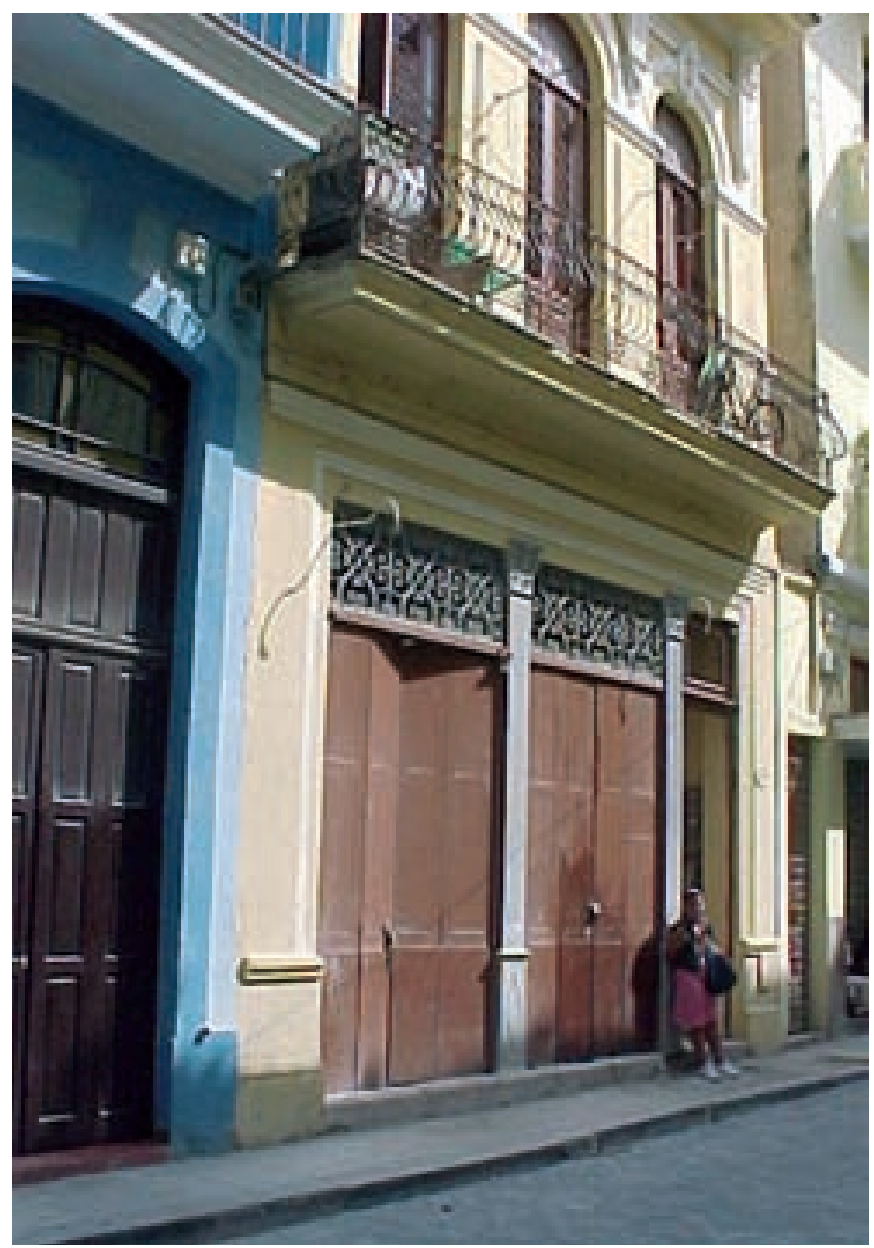

Fachada de edificio mixto en Teniente Rey 16 ésta por el desarrollo de series de habitaciones alineadas junto a un patio generalmente estrecho y alargado. Las instalaciones de baños, cocinas y áreas de lavar son compartidas en los espacios comunes. Estas edificaciones, destinadas a alojar a familias de muy escasos recursos en condiciones de habitabilidad deficientes, ya se había antes experimentado en otras áreas de la ciudad que se urbanizaban a lo largo del siglo XIX.

En cuanto a la vivienda más simple y a partir de la generalización de la cubierta plana, se propicia un crecimiento en altura que daría lugar a la solución definitivamente más dominante y caracterizadora de los ambientes urbanos. El mismo esquema de vivienda uniplanta se repite ahora en un segundo nivel - y más tarde en un tercero- de modo de obtener una mayor explotación del suelo urbano dentro del nuevo régimen de inquilinato que se intensifica.

Finalmente y derivado del auge de las funciones comerciales y productivas que desarrolla el territorio se va definiendo un nuevo tipo de inmueble que combina la planta baja comercial con plantas altas residenciales —edificios mixtos- que llegarán más tarde a caracterizar, con sus expresiones propias, algunos sectores y calles del conjunto histórico así como las extendidas calzadas comerciales de la Ciudad en desarrollo.

\section{El período republicano}

Con la implantación de la República, al inicio del siglo XX, $\mathrm{y}$ el cese de las guerras independentistas, un notable incremento de la actividad constructiva se concentra en la ciudad de La Habana reforzando su expansión. Dicha actividad, en La Habana Vieja, va acompañada de un sensible proceso de sustitución edilicia derivado del débil reconoci- 


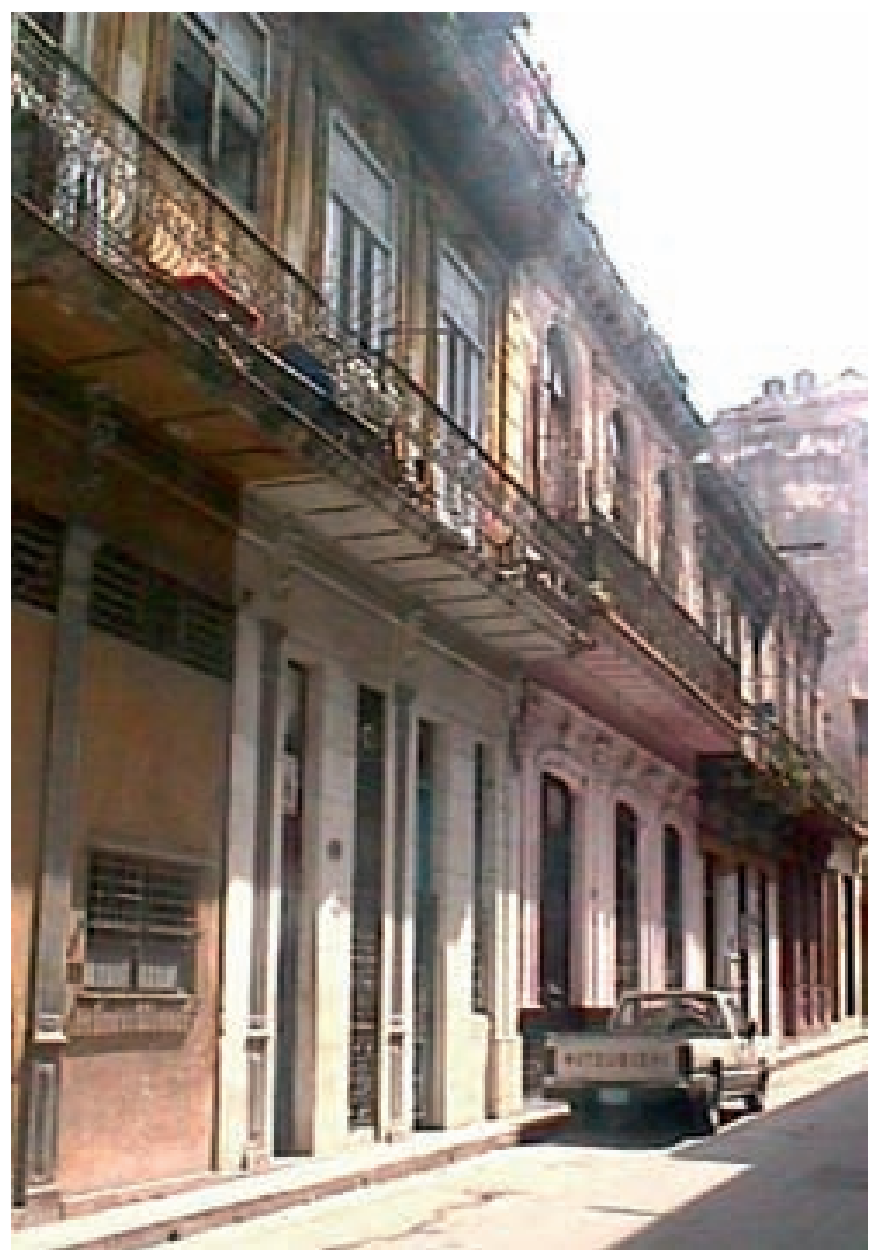

Conjunto de casas de sala y saleta en la calle Empedrado

miento de los valores patrimoniales del conjunto histórico, la falta de instrumentos legales en su defensa y los intereses especulativos que aprovecharon las ventajas de su carácter central.

Como soluciones habitacionales de la época el tipo de casa de "sala y saleta», desarrollada ahora en altura, será la más generalizada durante las primeras décadas del siglo XX. Adquieren también un fuerte peso, derivado de las funciones comerciales y productivas que se incrementan, aquellos inmuebles que combinan las plantas bajas comerciales con las altas residenciales, o sea, los llamados «edificios mixtos».

Éstos, que habían nacido en la segunda mitad del siglo XIX a través de la transformación de plantas bajas domésticas, nacen luego, en el siglo XX, con este carácter. Hacia los años treinta se incorporan a su vez los llamados «edificios de apartamentos» los cuales, por regla general, implicaron una ruptura con el contexto urbano.

A pesar de que en esta etapa del periodo republicano se sentaron las bases para la formación de una conciencia colectiva hacia la defensa de la cultura nacional y el recono-

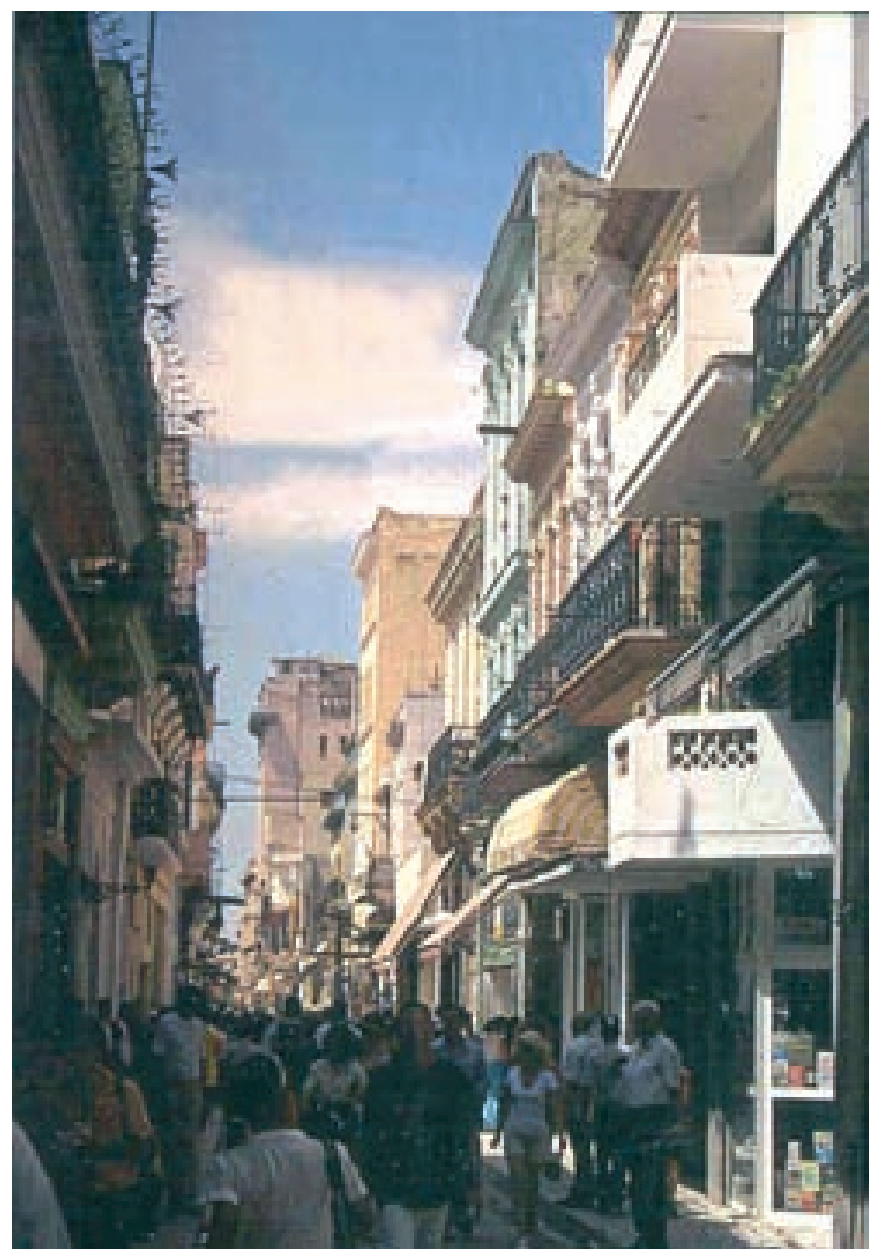

Conjunto de edificios mixtos en la calle Obispo

cimiento de nuestro patrimonio — centrada en la lucha sistemática de un grupo de importantes intelectuales y de la Oficina del Historiador, creada en 1938- no pudo evitarse la eliminación de numerosas edificaciones coloniales con el fin de lograr usos más intensos y rentables del suelo urbano. Lo anterior abrió el camino al despliegue dominante de la arquitectura republicana. Gracias a las condicionantes que imponían las Ordenanzas para la Construcción, provenientes de 1861, en cuanto a requisitos de puntales, alineación, medianería, vuelo de balcones y cornisas, entre otros aspectos, se favorecía que las nuevas edificaciones mantuvieran aún un diálogo armónico y coherente en la imagen urbana.

A pesar de ello, los turbios manejos políticos dieron, en carácter de «excepción", concesiones para la ejecución de obras de fuerte volumetría que transgredían lo regulado respecto a las alturas permitidas aunque su relación con el contexto resultaba menos antagónica debido a la adopción generalizada de los códigos del eclecticismo y a su buena factura. 


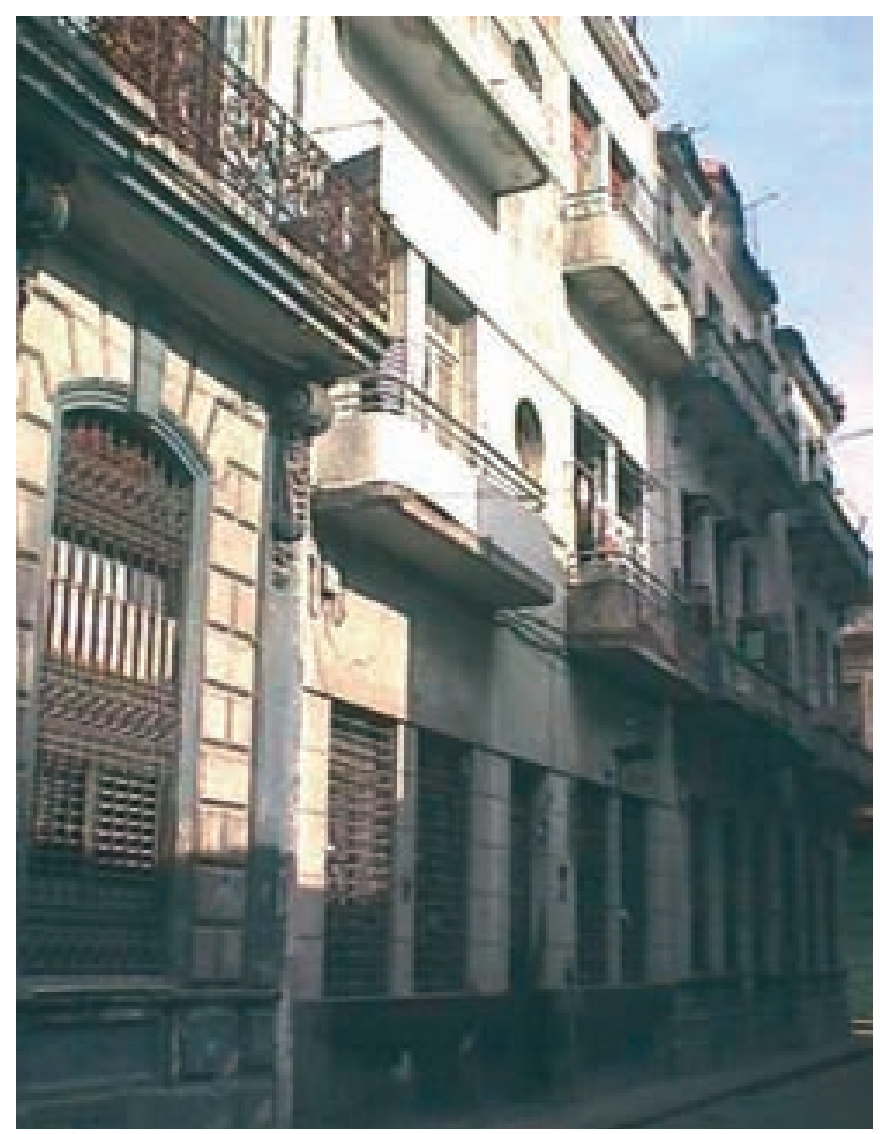

Soluciones republicanas de edificios de apartamentos: Cuba 156; Chacón 156

No ocurrió igual a partir de los años ' $40 \mathrm{y}$, sobre todo, en la década de los '50. La actividad constructiva - asocia$\mathrm{da}$ entonces a las expresiones del movimiento moderno-, se manifestó con una mayor libertad nada subordinada a los ambientes tradicionales. Se incorporarán así edificaciones de menor pobreza expresiva y, en ocasiones, enfatizadas por una volumetría contrastante.

Desde el punto de vista constructivo y en paralelo con estos procesos de sustitución edilicia, el fondo residencial había comenzado una etapa de acelerado deterioro derivado de la intensidad de uso que afectaba a la gran mayoría de las edificaciones coloniales. La capital, en la etapa republicana, recibía a un voluminoso número de familias que, procedentes de las empobrecidas áreas del interior del país, venían en busca de mejores oportunidades y, en muchos casos, como única opción a sus demandas educacionales y de salud. La antigua casa colonial, continuaba siendo el alojamiento económico por excelencia en medio de una centralidad insuperable.

Los cambios políticos ocurridos a fines de la década de los ' 50 paralizaron a tiempo el peligroso proceso de sustitución de las edificaciones con lo cual se logra preservar la alta coherencia y la riqueza que caracterizan a la imagen ur-
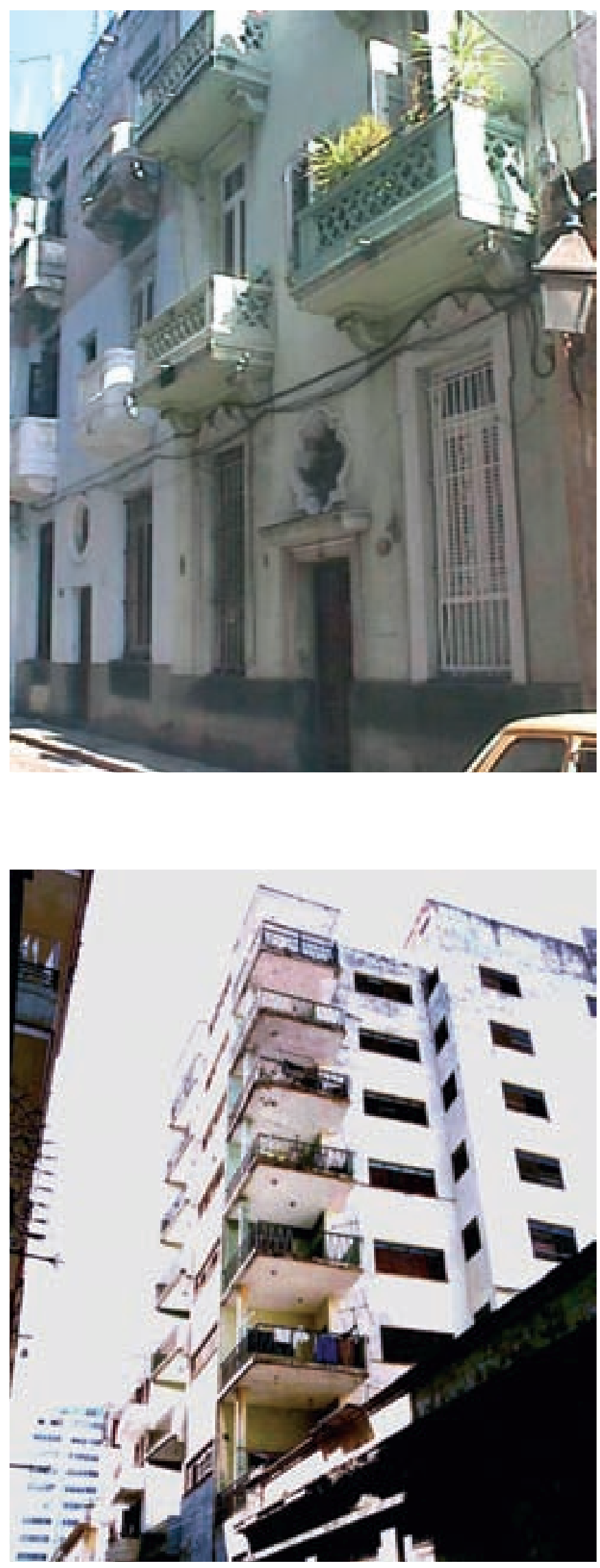

Solución de edificio de apartamentos en Aguiar 114 
bana de La Habana Vieja. La protección del patrimonio, como elemento clave dentro de la política cultural de la nación, deviene un objetivo importante desde las primeras etapas del período revolucionario.

\section{Una nueva etapa de intervención: la rehabilitación del conjunto urbano}

Sustentada en la indispensable base legal —-Leyes de Protección del Patrimonio Cultural y la Ley de los Monumentos Nacionales y Locales, ambas de 1977- y en la declaratoria de Monumento Nacional —de 1978_- el estado cubano decide enfrentar el complejo proceso de la restauración del Centro Histórico, misión asignada a la Oficina del Historiador de la Ciudad. El enorme reto nacerá condicionado por las adversas limitaciones económicas y una alarmante situación constructiva heredada por el valioso conjunto urbano que, en 1982, resultará además incorporado al listado del patrimonio cultural de la humanidad.

Enmarcado por planes quinquenales financiados por el Estado cubano los primeros planes de intervención constructiva adquieren una intención urbanística que tiene como centro de referencia la Plaza de Armas, sitio de fundación de la Ciudad. A partir de ésta, y a lo largo de los primeros ejes del desarrollo urbano, avanza el proceso de recuperación. La incredulidad y desconfianza que muchos sintieron respecto a las posibilidades de recuperación de la vieja ciudad va tornándose en admiración y asombro ante los atractivos resultados.

Las áreas recuperadas comienzan a despertar simultáneamente el interés turístico y, del aprovechamiento inteligente de este potencial, se vislumbran seguras ventajas. Predominan en este período los temas culturales en las funciones adquiridas por los inmuebles que se recuperan seguidas luego por las instalaciones de apoyo a la actividad turística.

Con relación a la vivienda y dentro de los intereses del rescate patrimonial, la experiencia fundamental es llevada por el conjunto de la Plaza Vieja. Sobre el antiguo y valioso grupo de edificaciones comienza a desarrollarse un proyecto urbano-arquitectónico que plantea, como objetivo fundamental, la conservación del carácter residencial que históricamente marcó a esta Plaza. Las limitaciones de recursos mantienen las obras de la plaza dentro de un lento ritmo durante la década de los ochenta. Tanto dichas obras como otras, que en general desarrollaba el Plan de Restauración del Centro Histórico, resultan afectadas ante la crisis económica que deberá enfrentar el país en los inicios de los años noventa derivada de la caída del bloque socialista.
Con el objetivo de evitar la paralización del importante programa de recuperación del patrimonio - subvencionado centralmente por el Estado cubano hasta ese momento - se toma la decisión, en el año 1993, de aprobar el decreto Ley 143, respaldo legal con que la Oficina del Historiador asumiría la continuación de dicho programa bajo un nuevo régimen autofinanciado. Comienza entonces a organizarse una estructura inversionista encarada a posibilitar una nueva dinámica que, apoyada en la conveniente explotación del patrimonio, sería capaz de generar los recursos necesarios para asegurar la continuidad del proceso.

Lo anterior se traduce así en un vertiginoso impulso constructivo y a la consiguiente expansión del área atendida. Paralelamente, las nuevas condiciones económicas posibilitan el fortalecimiento y la ampliación de programas de fuerte contenido social. Se destacan entre ellos los programas dirigidos a la vivienda, los temas de salud - consultorios médicos, Clínica Infantil, Hogar Materno, Centro Geriátrico-; los temas de educación —Biblioteca Pública Martínez Villena, las Aulas-Museos-, el Asilo de Ancianas en el antiguo Convento de Belén.

De este modo el patrimonio recuperado comienza no sólo a asegurar la continuidad del proceso, sino a ser capaz de financiar, cada vez con mayores recursos, la rehabilitación socioeconómica que proporcionará la integralidad esperada al proyecto del Centro Histórico.

\section{Programas fundamentales dirigidos a la atención a la vivienda}

La actuación dirigida a la transformación del negativo panorama del fondo residencial del Centro Histórico se orientó, a partir del año 1994, en dos direcciones fundamentales. Una de ellas sería la creación de nuevos fondos en áreas urbanas externas, lo cual debía facilitar la rapidez de los procesos constructivos gracias a las tecnologías consideradas, al mismo tiempo que evitaba los riesgos derivados de la inserción contemporánea — condicionada por los escasos recursos y la premura- en contextos tan cualificados como La Habana Vieja.

Dentro del conjunto histórico prevalecerían las obras de restauración y de rehabilitación de edificaciones existentes. Las principales áreas de actuación en este sentido serían, de un lado, el novedoso Plan Integral de Rehabilitación del barrio de San Isidro, del otro, la continuidad y aceleramiento de la recuperación del valioso conjunto de la Plaza Vieja.

$\mathrm{El}$ incremento del ritmo constructivo - gracias al fortalecimiento económico de la Oficina derivado de su novedoso modelo de gestión- permitió, en breve plazo, la in- 


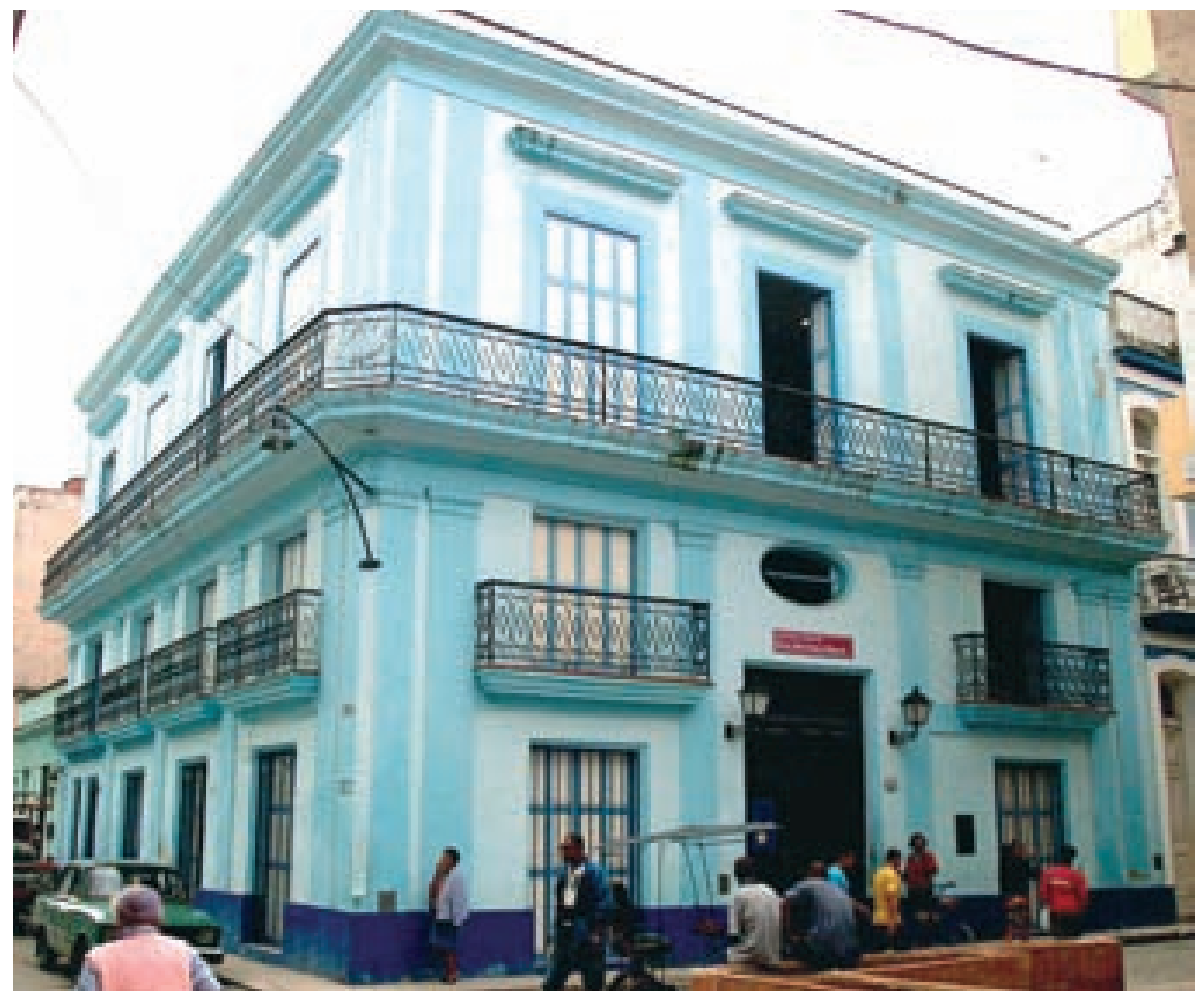

Escuela primaria Mariano Martí, casa del siglo XIX recuperada a partir de un estado ruinoso corporación de programas dirigidos particularmente a la vivienda, algunos de los cuales contaron, además, con el apoyo de la cooperación internacional. La creación de nuevos fondos residenciales comienza entonces a orientarse, paralelamente, hacia los espacios disponibles del tejido histórico asumiéndose ahora el reto representado por la inserción contemporánea.

Las principales directrices que debe asumir el complejo proceso de atención a los problemas habitacionales en correspondencia con la política que plantea la conservación del carácter residencial del Centro Histórico están contenidas en el documento del Plan Estratégico elaborado en el 2001, específicamente en el capítulo de la Estrategia para la vivienda, donde se señalan los objetivos y lineamientos convenientes para encarar este problema.

Entre los principales programas que se desarrollan actualmente dirigidos a la solución paulatina de la problemática habitacional se destacan:

\section{El Plan de Rehabilitación Integral del Barrio de San Isidro}

El mismo comprende un grupo de subprogramas que atienden la reparación, la rehabilitación y el mantenimiento de las viviendas existentes; la creación y recuperación de los servicios locales; el mejoramiento de la infraestructura técnica; la reactivación de la economía local; el rescate y fortalecimiento de las tradiciones populares; entre otros objetivos.

\section{La creación de nuevos fondos de vivienda}

Incluye el programa de construcción de nuevas viviendas a ejecutar fuera del territorio, fundamentalmente en nuevas urbanizaciones como Alamar y Capdevila. De manera reciente se ha dado inicio también a la ejecución de nuevos fondos al interior del propio Centro Histórico implicando ello una mayor exigencia en cuanto a la calidad resultante de las soluciones.

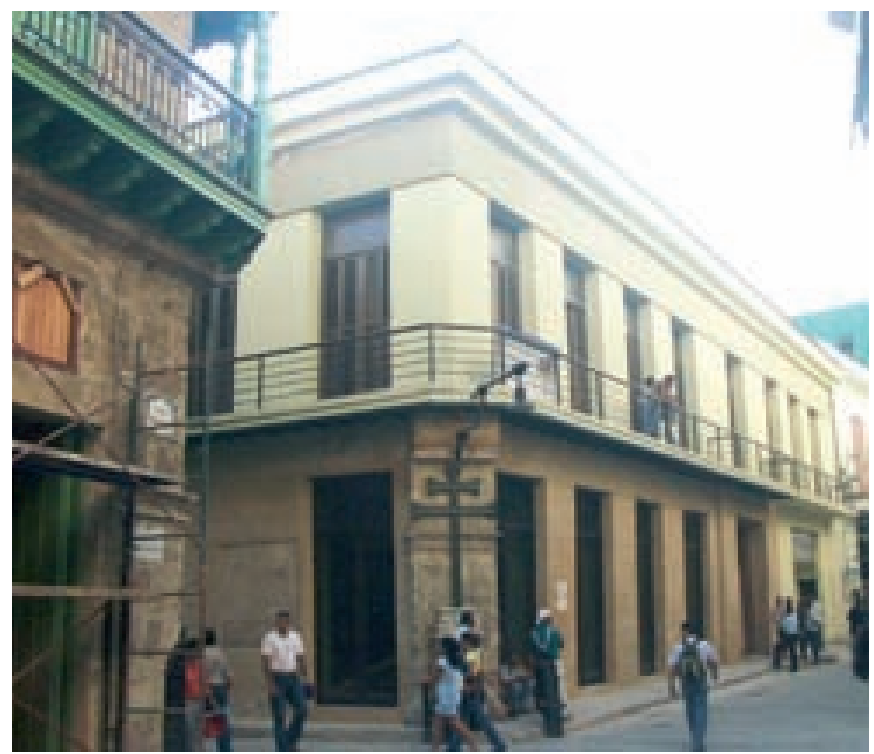

Nuevas viviendas en la antigua casa de La Cruz Verde, Amargura y Mercaderes 

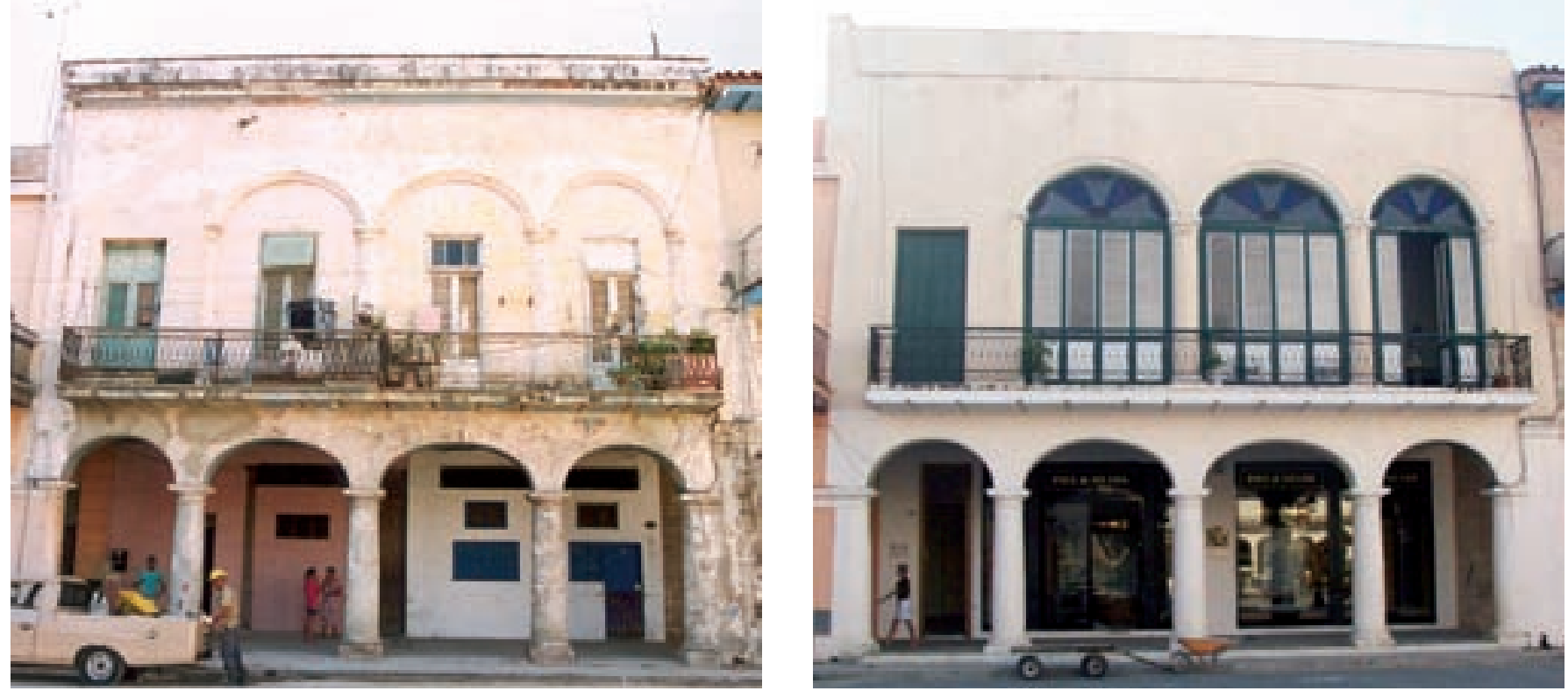

Muralla 103-105, en la Plaza Vieja, antes y después de su rehabilitación. Comercio en la planta baja y viviendas en las altas

Estos nuevos fondos posibilitan la reubicación de las familias afectadas a causa de los cambios de uso requeridos, así como por las propias intervenciones de rehabilitación que implican la reducción de los núcleos ocupantes en la mayoría de las edificaciones que se intervienen. Apoyan en los últimos tiempos al fortalecimiento de este programa el PDHL, el estado belga, el estado de Canadá, entre otros.

\section{La creación de viviendas de tránsito}

Se han desarrollado soluciones a partir de la nueva construcción, como por ejemplo, la Comunidad Provisoria de la calle Muralla, que posibilita el tránsito de las familias vinculadas al plan de rehabilitación del conjunto monumental Plaza Vieja. Otras soluciones se producen por medio de la adaptación de locales existentes disponibles.

\section{Intervenciones de reparación y rehabilitación de viviendas que integran las áreas priorizadas del Centro Histórico}

Se concentran estas intervenciones en el Sector Catedral Plaza Vieja, área que incluye a cuatro de las integrantes del sistema de Plazas Principales de La Habana Vieja. Con la reciente incorporación al proceso del proyecto de recuperación de la Plaza del Cristo se desarrollan también diversas obras a lo largo de la calle Teniente Rey.

\section{Recuperación de viviendas en la manzana 148}

Consiste en un proyecto integral dirigido a la recuperación de un interesante conjunto edificado vinculado — con sus instalaciones especializadas-, a la tradición farmacéutica de La Habana Vieja.

Un importante grupo de edificios de origen doméstico podrá recuperar de este modo su función inicial con la creación de nuevas y confortables viviendas. Las mismas posibilitarán la liberación del antiguo y valioso complejo religioso de Las Teresas, actualmente ocupado por numerosas familias que podrán entonces ser trasladadas a las nuevas viviendas obtenidas. De este modo podrá procederse a la restauración del importante monumento.

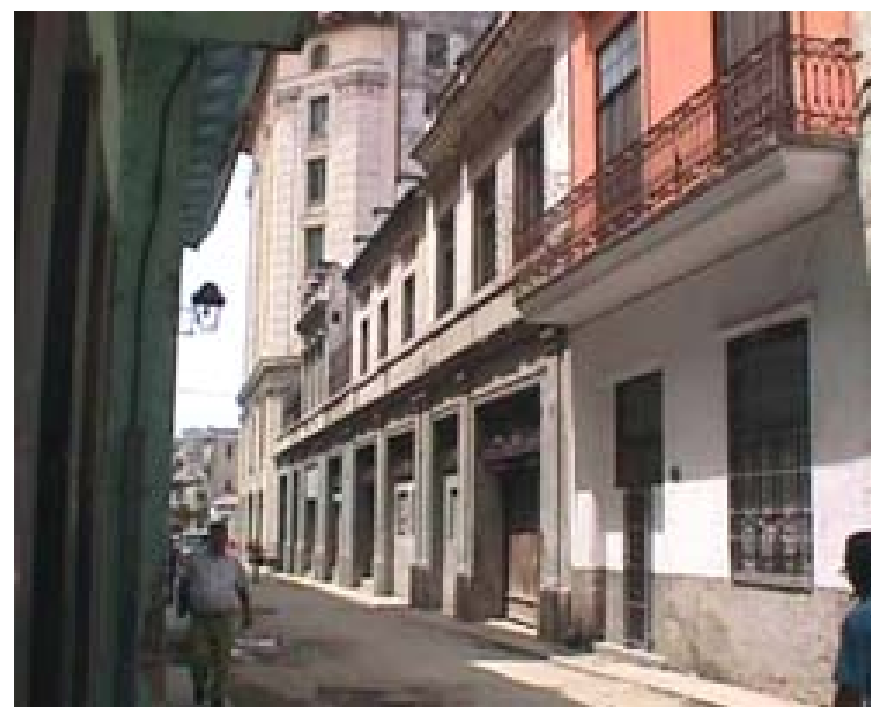

Manzana 148, vista por la calle Compostela 


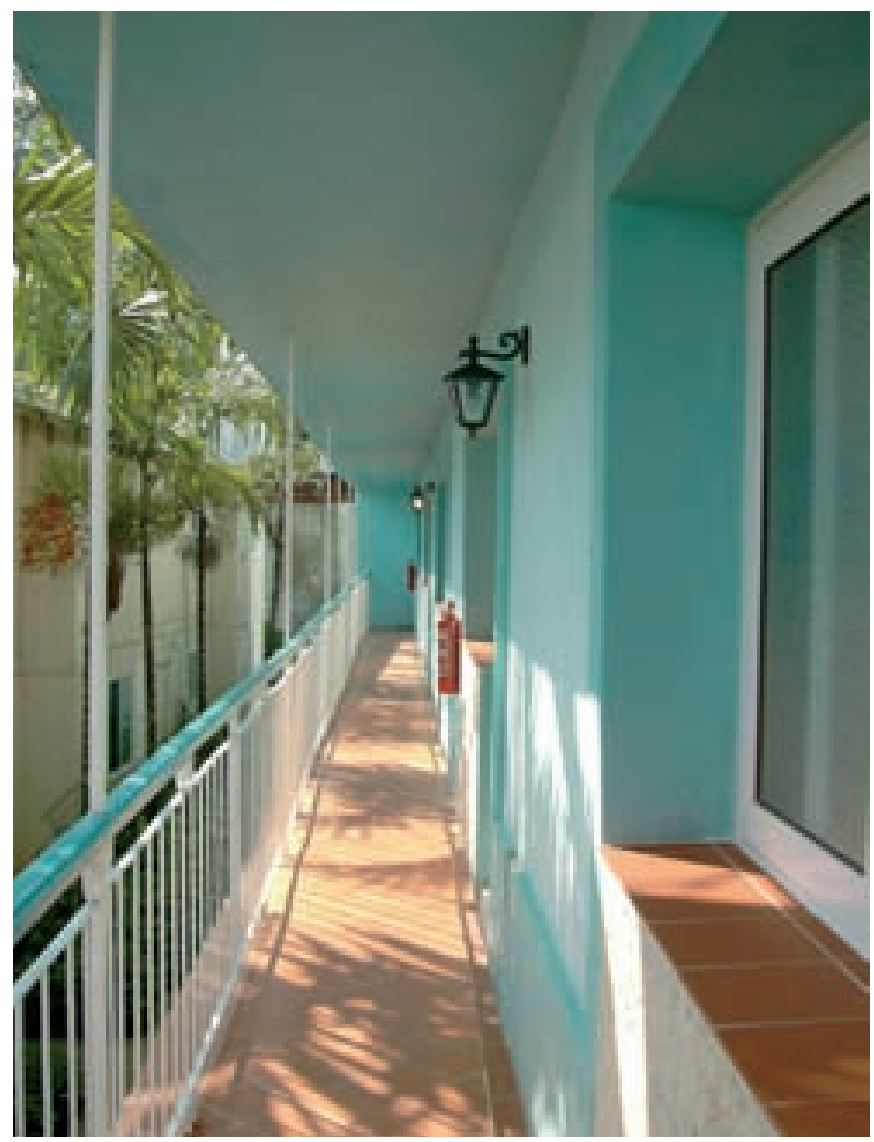

Primera experiencia en la esquina de Cuba y Muralla

\section{El sistema de Residencias Protegidas para Adultos Mayores}

Constituye una nueva experiencia dentro del tema de la vivienda dirigida a mejorar la atención a la población de la tercera edad con soluciones apropiadas y en correspondencia con la estrategia general planteada para el Centro Histórico. Cuenta con una primera obra recién concluida con el apoyo del PDHL y la ciudad de Florencia de la región toscana de Italia. Otra instalación de este tipo se ejecuta al interior de la manzana 148 , con financiamiento del país vasco, mientras que otras previstas se encuentran en fase de proyecto y/o en definición del financiamiento necesario.

\section{Reanimación de conjuntos de viviendas por concepto de obras inducidas}

Se trata de intervenciones menores dirigidas a la impermeabilización de cubiertas, el control de filtraciones, la reparación de las instalaciones hidrosanitarias y la recuperación de fachadas. Estas obras posibilitan, entre otros objetivos, mejorar la calidad de la imagen urbana. Dichas acciones aseguran su financiamiento a partir del presupuesto general de otras obras mayores, de las cuales constituyen su contexto ambiental inmediato.

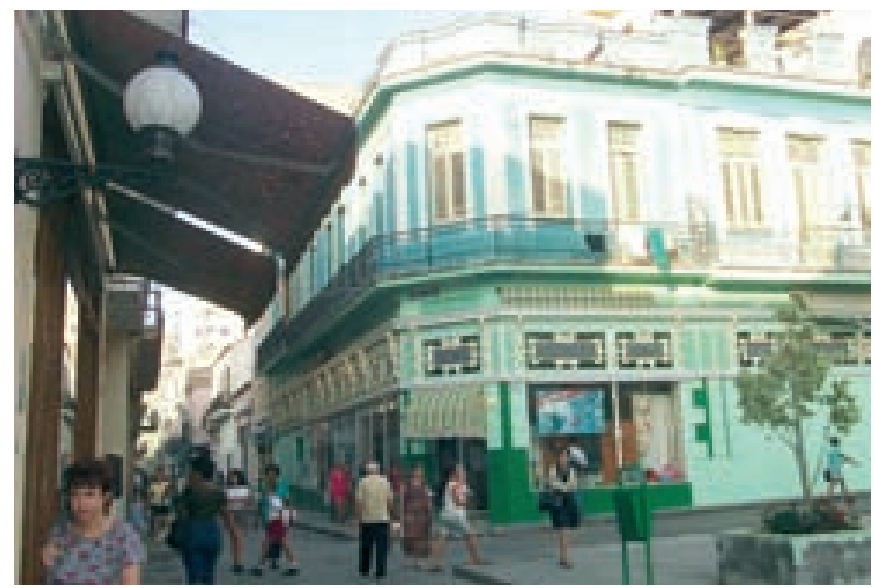

Calle Obispo

Obras vinculadas a la recuperación de la actividad comercial en la calle Obispo

Se trata de reparaciones interiores, impermeabilización de cubiertas y mejoras de las fachadas de los edificios de vivienda cuyas plantas bajas comerciales constituyen el objeto de un programa de revitalización de la tradicional actividad comercial.

\section{Programa de Emergencia ante Derrumbes}

Con el apoyo financiero de la Cooperación Italiana se desarrolló este programa dirigido a contrarrestar la tendencia a los derrumbes de los edificios de vivienda afectados por el fuerte deterioro constructivo. Como tal se considera a aquellas acciones que, con los recursos mínimos indispensables, van dirigidas a asegurar la continuidad de uso de las edificaciones dañadas y con riesgos de derrumbes, hasta tanto puedan éstas ser objeto de las acciones más profundas requeridas, generalmente, la rehabilitación. La intervención, concretamente, permitió recuperar la estabilidad estructural de un grupo de inmuebles $y$, paralelamente, eliminar las causas que provocaron el deterioro, por lo general asociadas a la humedad y a las filtraciones. Este programa, de gran impacto para la seguridad de la población, asegurará su continuidad por medio de diversas vías.

De la continuidad y el rigor con que se conduzcan todos estos programas dependerá el éxito y la celeridad de la rehabilitación con urgencia demandada por el hábitat de La Habana Vieja, concebido éste último no solo como sistema edificado, sino en su carácter integral, tal como corresponde a su condición de función urbana principal. De modo paralelo, la dominante arquitectura doméstica heredada deberá asimilar la intervención que le posibilite brindar una mejor respuesta a los requerimientos contemporáneos y ambientales, dentro de una obligada compatibilidad con la protección de los valores culturales sobre los cuales se sustenta la categoría patrimonial del Centro Histórico. 